\title{
Correction to: Occurrence of pharmaceuticals in the eastern gulf of Finland (Russia)
}

\section{Ekaterina Chernova ${ }^{1}$ (D) $\cdot$ Zoya Zhakovskaya ${ }^{1} \cdot$ Nadezhda Berezina $^{2}$}

Published online: 6 August 2021

(C) Springer-Verlag GmbH Germany, part of Springer Nature 2021

\section{Correction to: Environmental Science and Pollution}

Research

https://doi.org/10.1007/s11356-021-15250-1

The Funding text is missing in the published proof.

The original article has been corrected.

Publisher's note Springer Nature remains neutral with regard to jurisdictional claims in published maps and institutional affiliations.

The online version of the original article can be found at https://doi.org/ $10.1007 / \mathrm{s} 11356-021-15250-1$

\section{Ekaterina Chernova}

s3561389@yandex.ru

1 St. Petersburg Federal Research Center of the Russian Academy of Sciences (SPC RAS), Scientific Research Centre for Ecological Safety of the Russian Academy of Sciences, 18, Korpusnaya st, St. Petersburg 197110, Russia

2 Zoological Institute, Russian Academy of Sciences, Universitetskaya embankment, 1, St. Petersburg 199034, Russia 